\title{
Health-Related Quality of Life in Multiple System Atrophy using EQ-5D-5L: A Large Cross-Sectional Study in China
}

\author{
Yi Xiao \\ West China School of Medicine: Sichuan University West China Hospital \\ Lingyu Zhang \\ West China Hospital of Medicine: Sichuan University West China Hospital \\ Qianqian Wei \\ Sichuan University West China Hospital \\ Ruwei Ou \\ Sichuan University West China Hospital \\ Yanbing Hou \\ Sichuan University West China Hospital \\ Kuncheng Liu \\ Sichuan University West China Hospital \\ Junyu Lin \\ Sichuan University West China Hospital \\ Tianmi Yang \\ Sichuan University West China Hospital \\ HuiFang Shang ( $\square$ hfshang2002@126.com) \\ Sichuan University West China Hospital https://orcid.org/0000-0003-0947-1151
}

\section{Research Article}

Keywords: Multiple system atrophy, health-related quality of life, EQ-5D-5L, fatigue, sleep

Posted Date: November 3rd, 2021

DOI: https://doi.org/10.21203/rs.3.rs-892567/v2

License: (a) (1) This work is licensed under a Creative Commons Attribution 4.0 International License. Read Full License 


\section{Abstract}

Background Multiple system atrophy (MSA) is a rare neurodegenerative disease, featuring autonomic failure plus parkinsonism and/or cerebellar ataxia. These symptoms impact the health-related quality of life (HRQoL) of MSA.

Objective We aimed to evaluate the HRQoL of MSA with a preference-based instrument, the five-level EuroQol five-dimensions questionnaire (EQ-5D-5L), for the first time.

Methods EQ-5D-5L was used to evaluate the HRQoL. The result of HRQoL was displayed as heath utility index and visual analog scale (EQ-VAS) score. Specific scales were used to measure the disease severity, cognition, frontal lobe function, anxiety, depression, fatigue, and sleep disorders. The forward logistic model was used to explore the determinants of HRQoL in MSA.

Results A total of 205 patients with cerebellar variant (MSA-C, 53.9\%) and 175 patients with parkinsonian variant (MSA-P, 46.1\%) patients were included in the study. The mean scores of the health utility index and EQ-VAS were 0.558 and 59.5 , respectively. Mobility was reported by the largest proportion (92.1\%) of MSA patients, followed by usual activities (88.7\%), self-care (81.3\%), anxiety/depression (72.1\%), and pain/discomfort (53.9\%). The determinants of the lower health utility index in MSA were female sex, greater total Unified Multiple System Atrophy Rating Scale (UMSARS) scores, fatigue, and Parkinson's disease-related sleep problems (PD-SP). Lower EQ-VAS score was associated with greater total UMSARS scores, fatigue, PD-SP, and anxiety symptom. MSA-P patients reported more frequent problems in pain/discomfort than MSA-C patients, while MSA-C patients reported more problems in mobility than MSA-P patients.

Conclusion Patients with MSA had poor HRQoL evaluated by EQ-5D-5L. The most frequent affected problem is mobility in the Chinese MSA population. Besides the severity of MSA, fatigue, PD-SP and anxiety were determinants for poor HRQoL. Our research provides important information to improve the health status of patients with MSA.

\section{Introduction}

Multiple system atrophy (MSA) is a rare, rapidly progressive neurodegenerative disease featured with autonomic failure, parkinsonism, and/or cerebellar ataxia. To date, the etiology of MSA is still uncertain and no cure for MSA is available. MSA can be subclassified into a cerebellar variant (MSA-C) and a parkinsonian variant (MSA-P) according to the predominant motor symptom. [1] Except for experiencing severe disability in a short duration, many patients undergo various non-motor symptoms including urinary incontinence, dysarthria, depression, anxiety, sleep disorders, and so on. In addition, non-motor symptoms such as depression, anxiety, and autonomic deficit have a negative impact on the patients' lives and lead to a heavy disease burden. [2-5]

Patients with MSA were reported to have a poorer health-related quality of life (HRQoL) than healthy controls and patients with Parkinson's disease (PD). [5, 6] Compared to the common scale such as Parkinson's disease Questionnaire-39 item version (PDQ39) which was used to measure the quality of life (QoL) of PD patients, the common symptoms of autonomic and cerebellar in MSA were not adequately reflected by PDQ-39. [7] The five-level EuroQol five-dimensions questionnaire (EQ-5D-5L), a preferencebased instrument developed by EuroQol groups, is one of the most frequently used tools to evaluate HRQoL worldwide. [8] It can be used to estimate quality-adjusted life-years (QALYs), helping public health specialists and epidemiologists to plan interventions to improve patient's health status. The EQ-5D-5L was developed from the 3-level version of EQ-5D (EQ-5D-3L) and was proved to have some advantages over EQ-5D-3L. [9] However, there were only a few studies focused on the HRQoL of MSA by using EQ-5D-3L.[3-5, 10] These studies found that the most frequently affected dimensions in MSA were mobility, self-care, and usual activities. [3-5, 10] Besides the severity of the disease $[4-6,11]$, some studies found that depression was the determinant of HRQoL of MSA. [3, 5] No study on QoL of MSA evaluated by using EQ-5D-5L was available. Moreover, there was no study focused on the impact of nonmotor symptoms measuring by comprehensive assessment scales on the QoL evaluated by using EQ-5D-5L in MSA.

Therefore, in the current study, we aimed to fill the gap to evaluate the HRQoL of MSA using EQ-5D-5L. Additionally, we used specific scales to measure the severity of non-motor symptoms including cognition, frontal lobe dysfunction, depression, anxiety, sleep disorders, and fatigue. We aimed to explore the determinants of HRQoL in MSA and the differences between MSA-C and MSA-P.

\section{Method}




\section{Patients and Clinical features evaluation}

Consecutive patients were recruited from the Department of Neurology, West China Hospital, Sichuan University from March 2018 to July 2021. All the patients reached the diagnostic criteria of probable MSA through comprehensive medical history reviewing and physical examination. [1] The exclusion criteria were: 1) magnetic resonance imaging scan, spinal cerebellar ataxia genetic tests (SCA1 $2,3,6,7)$, or blood test indicating a diagnosis of other neurological diseases; 2 ) did not finish the whole interview because of dysarthria, weakness, or other reasons. This study was approved by the Ethics Committee of West China Hospital of Sichuan University and informed consent forms were signed by all subjects.

The clinical data were collected by experienced neurologists during a face-to-face interview. The demographic characteristics including age, sex, education, disease duration, and age of onset were collected. The disease severity was measured by the Unified Multiple System Atrophy Rating Scale (UMSARS). [12] The total UMSARS score was the sum of parts I and II. The orthostatic hypotension $(\mathrm{OH})$ was defined as the drop of systolic blood pressure $\geq 30 \mathrm{~mm} \mathrm{Hg}$ and/or diastolic blood pressure $\geq 15 \mathrm{~mm} \mathrm{Hg}$. The global cognitive function was evaluated using the Montreal Cognitive Assessment (MoCA). [13] The cognitive impairment was defined as MoCA < 19 for individuals with no more than 6 years of education, MoCA $<22$ for individuals with 7 to 12 years of education, and MoCA < 24 for individuals with more than 12 years of education. [14] Frontal lobe dysfunction was defined as the frontal assessment battery (FAB) score < 16. [15] The depressive and anxiety emotion were respectively defined as the Hamilton Depression Rating Scale (HAMD, 24 items) score $\geq 8$ [16] and the Hamilton Anxiety Rating Scale (HAMA) score $\geq 6$. [17] Fatigue was defined as the mean score of Fatigue Severity Scale (FSS) $\geq 4$. [18] Parkinson's disease-related sleep problems (PD-SP) were defined as the Parkinson's Disease Sleep Scale 2nd version (PDSS-2) score $\geq 18$. [19] Excessive daytime sleepiness (EDS) was defined as the Epworth Sleepiness Scale (ESS) score $\geq 10$. [20] Rapid eye movement sleep behavioral disorder (RBD) was defined as the Rapid Eye Movement Sleep Behavior Disorder Screening Questionnaire (RBDSQ) score $\geq 5$. [21]

\section{Assessment Of Hrqol}

The HRQoL was evaluated using EQ-5D-5L. This scale was developed by the EuroQol Group and was used in evaluating healthy populations and patients with different diseases. [8] The EQ-5D-5L was designed for self-completion. It contains a questionnaire with five dimensions and a vertical visual analogue scale (EQ-VAS). The five dimensions are Mobility, Self-Care, Usual Activities, Pain/Discomfort, and Anxiety/Depression. Each dimension has five levels ranging from "no problems", "slight-moderate-severe" problems, to "unable to do". Descriptive levels of each dimension were dichotomized to "no problems"(level one) and "problems" (level two to five). The descriptive scores of the five dimensions were converted to health utility values according to the EQ-5D-5L value set for China. [22] The health utility values are anchored at 0 (death) and 1 (perfect health) and can be used to assess QALYs. The results of EQ-VAS were self-rated scores marked from 0 to 100, reflecting the patient's opinion on their overall health on the day of the interview.

\section{Statistical analysis}

First, the Kruskal-Wallis test was performed as the normality test. Mann-Whitney test was conducted to compare the health utility values and EQ-VAS scores of patients in different subgroups regarding sex, subtype, frontal lobe dysfunction, cognitive impairment, depressive emotion, anxiety emotion, EDS, RBD, PD-SP, and fatigue. T-test or Chi-square tests were conducted to compare demographic characteristics between MSA-C and MSA-P for continuous and categorical variables. Spearman's correlation analysis was conducted to explore relationships between EQ-5D-5L scores and clinical symptoms. Forward stepwise multiple logistic regression analysis was used to explore the potential determinants of HRQoL in MSA and two subtypes. Patients were divided into two groups according to the median of the health utility value and EQ-VAS score. The health utility value or EQ-VAS score was used as the dependent variable. The demographic and clinical variables were included in the model as independent variables. A level of $P$ $<0.05$ was set for a variable entered into the model and $P>0.10$ for removal from the model. Statistically significant was considered as $\mathrm{P}<0.05$. All analyses were performed using SPSS 22.0 (SPSS, Inc., Chicago, IL, USA).

\section{Results}




\section{Clinical characteristics of MSA and two subtypes}

Finally, 205 MSA-C (53.9\%) and 175 MSA-P (46.1\%) were included in the study. The clinical characteristics of patients are displayed in Table 1. The average age and disease duration were 60.3 years old and 2.6 years respectively. There were 212 male patients (55.8\%) and 168 females (44.2\%). Patients with MSA-P had older age and age of onset and higher scores of PDSS-2 and ESS than patients with MSA-C. Patients with MSA-C had a higher proportion of $\mathrm{OH}$ and higher scores of RBDSQ than patients with MSA-P. There were no significant differences in other clinical features between the two subtypes.

Table 1

Demographic and clinical characteristics of patients with MSA and subtypes.

\begin{tabular}{|c|c|c|c|c|}
\hline & Total $(n=380)$ & MSA-C $(n=205)$ & MSA-P $(n=175)$ & $P$ value \\
\hline Sex (male) & $212(55.8 \%)$ & $117(57.1 \%)$ & $95(54.3 \%)$ & 0.586 \\
\hline Age (years) & $60.3(9.3)$ & $58.6(9.2)$ & $62.3(9.0)$ & $<0.001^{\star}$ \\
\hline Age of onset (years) & $57.7(9.1)$ & $56.1(9.1)$ & $59.5(8.9)$ & $<0.001^{\star}$ \\
\hline Disease duration (years) & $2.6(1.5)$ & $2.6(1.4)$ & $2.7(1.6)$ & 0.295 \\
\hline Education (years) & $9.6(3.7)$ & $9.6(3.6)$ & $9.6(3.8)$ & 0.920 \\
\hline UMSARS- $\rrbracket$ & $16.6(6.7)$ & $16.8(6.7)$ & $16.4(6.7)$ & 0.536 \\
\hline UMSARS- $\bigotimes$ & $18.4(6.9)$ & $18.0(6.7)$ & $18.8(7.2)$ & 0.294 \\
\hline UMSARS- $\rrbracket$ & $2.2(1.0)$ & $2.2(1.0)$ & $2.2(1.1)$ & 0.981 \\
\hline UMSARS-total & $35.1(12.7)$ & $34.9(12.4)$ & $35.2(13.1)$ & 0.806 \\
\hline FAB & $14.4(2.9)$ & $14.5(2.8)$ & $14.3(2.9)$ & 0.613 \\
\hline MoCA & $21.9(5.0)$ & $21.8(4.8)$ & $22.0(5.3)$ & 0.755 \\
\hline FSS & $37.9(19.3)$ & $37.0(19.8)$ & $38.9(18.7)$ & 0.332 \\
\hline PDSS-2 & $11.6(7.5)$ & $10.4(6.9)$ & $13.0(8.0)$ & $0.001^{*}$ \\
\hline ESS & $5.7(4.9)$ & $5.1(4.6)$ & $6.5(5.1)$ & $0.004^{*}$ \\
\hline RBDSQ & $5.5(3.6)$ & $6.0(3.7)$ & $5.0(3.4)$ & $0.007 *$ \\
\hline HAMD & $12.5(8.1)$ & $12.4(8.0)$ & $12.7(8.3)$ & 0.737 \\
\hline HAMA & $10.2(7.0)$ & $9.9(6.7)$ & $10.6(7.4)$ & 0.354 \\
\hline $\mathrm{OH}$ & 155 (40.8\%) & $94(45.9 \%)$ & $61(34.9 \%)$ & $0.030 *$ \\
\hline
\end{tabular}

Continuous variables are displayed as mean scores and standard deviation. Dichotomous variables are displayed as numbers and percentages. T-test or Chi-square test was performed comparing characteristics between MSA-C and MSA-P. *Significant difference.

Abbreviations: MSA: multiple system atrophy. MSA-P: MSA with predominately parkinsonism. MSA-C: MSA with predominately cerebellar ataxia. UMSARS: the Unified Multiple System Atrophy Rating Scale. FAB: the frontal assessment battery. MoCA: the Montreal Cognitive Assessment. FSS: the Fatigue Severity Scale. PDSS-2: the Parkinson's Disease Sleep Scale 2nd version. ESS: the Epworth Sleepiness Scale. RBDSQ: Rapid Eye Movement Sleep Behavior Disorder Screening Questionnaire. HAMD: the Hamilton Depression Rating Scale. HAMA: the Hamilton Anxiety Rating Scale. OH: orthostatic hypotension.

\section{Eq-5d-5I In Msa And Different Subgroups}

The mean EQ-VAS score for MSA was 59.5 (SD: 17.81) and the mean health utility value was 0.558 (SD: 0.276 ). The health utility values and EQ-VAS scores of different subgroups are displayed in Table 2. Female patients and subjects with frontal lobe dysfunction, cognitive impairment, depression, anxiety, EDS, PD-SP, and fatigue had lower health utility values. Female patients and patients with $\mathrm{OH}$, depression, anxiety, PD-SP, and fatigue had lower EQ-VAS scores. No significant differences in the health utility 
values and EQ-VAS were observed between patients with MSA-C and MSA-P. The frequency of five levels in five dimensions of EQ5D-5L in total MSA patients and two subtypes of patients are shown in Figure 1. For each dimension, mobility was reported by $92.1 \%$ of MSA patients, followed by usual activities (88.7\%), self-care (81.3\%), anxiety/depression (72.1\%), and pain/discomfort (53.9\%). The frequencies of reported problems of each dimension in MSA-C and MSA-P are displayed in Figure 2. The most common problem was mobility in both MSA-C and MSA-P patients, followed by usual activities, self-care, anxiety/depression, and pain/discomfort. The frequency of reported problems of pain/discomfort in patients with MSA-P was significantly higher than that in patients with MSA-C while the frequency of reported problems of mobility in patients with MSA-P was significantly lower than that in patients with MSA-C.

Table 2

Health utility index and EQ-VAS scores regarding the clinical features in MSA.

\begin{tabular}{|c|c|c|c|c|c|c|}
\hline & Groups & Number & Health utility value & $P$ value & EQ-VAS score & $P$ value \\
\hline \multirow[t]{2}{*}{ Sex } & Male & 212 & $0.687(0.485-0.792)$ & \multirow[t]{2}{*}{$<0.001^{*}$} & $60(50-70)$ & \multirow[t]{2}{*}{$0.014^{*}$} \\
\hline & female & 168 & $0.513(0.281-0.734)$ & & $60(50-70)$ & \\
\hline \multirow[t]{2}{*}{ Subtypes } & MSA-C & 205 & $0.606(0.363-0.760)$ & \multirow[t]{2}{*}{0.498} & $60(50-70)$ & \multirow[t]{2}{*}{0.148} \\
\hline & MSA-P & 175 & $0.638(0.363-0.792)$ & & $60(50-70)$ & \\
\hline \multirow[t]{2}{*}{$\mathrm{OH}$} & No & 225 & $0.638(0.400-0.783)$ & \multirow[t]{2}{*}{0.118} & $60(50-70)$ & \multirow[t]{2}{*}{$0.045^{\star}$} \\
\hline & Yes & 155 & $0.571(0.347-0.778)$ & & $60(50-70)$ & \\
\hline \multirow[t]{2}{*}{ FLD } & No & 164 & $0.691(0.446-0.792)$ & \multirow[t]{2}{*}{$<0.001^{*}$} & $60(50-70)$ & \multirow[t]{2}{*}{0.051} \\
\hline & Yes & 216 & $0.566(0.290-0.734)$ & & $60(50-70)$ & \\
\hline \multirow[t]{2}{*}{$\mathrm{Cl}$} & No & 213 & $0.691(0.444-0.792)$ & \multirow[t]{2}{*}{$<0.001^{\star}$} & $60(50-70)$ & \multirow[t]{2}{*}{0.112} \\
\hline & Yes & 167 & $0.513(0.208-0.724)$ & & $60(50-70)$ & \\
\hline \multirow[t]{2}{*}{ Depressive mood } & No & 130 & $0.749(0.595-0.841)$ & \multirow[t]{2}{*}{$<0.001^{*}$} & $70(58.75-80)$ & \multirow[t]{2}{*}{$<0.001^{\star}$} \\
\hline & Yes & 250 & $0.511(0.259-0.723)$ & & $60(50-70)$ & \\
\hline \multirow[t]{2}{*}{ Anxiety mood } & No & 109 & $0.748(0.592-0.841)$ & \multirow[t]{2}{*}{$<0.001^{*}$} & $70(60-80)$ & \multirow[t]{2}{*}{$<0.001^{*}$} \\
\hline & Yes & 271 & $0.513(0.296-0.734)$ & & $60(50-70)$ & \\
\hline \multirow[t]{2}{*}{ EDS } & No & 300 & $0.638(0.375-0.792)$ & \multirow[t]{2}{*}{$0.021^{*}$} & $60(50-70)$ & \multirow[t]{2}{*}{0.327} \\
\hline & Yes & 80 & $0.513(0.245-0.734)$ & & $60(50-70)$ & \\
\hline \multirow[t]{2}{*}{ RBD } & No & 171 & $0.642(0.438-0.783)$ & \multirow[t]{2}{*}{0.089} & $60(50-70)$ & \multirow[t]{2}{*}{0.318} \\
\hline & Yes & 209 & $0.513(0.281-0.734)$ & & $60(50-70)$ & \\
\hline \multirow[t]{2}{*}{ PD-SP } & No & 304 & $0.669(0.441-0.792)$ & \multirow[t]{2}{*}{$<0.001^{\star}$} & $60(50-70)$ & \multirow[t]{2}{*}{$<0.001^{*}$} \\
\hline & Yes & 76 & $0.431(0.134-0.573)$ & & $60(50-70)$ & \\
\hline \multirow[t]{2}{*}{ Fatigue } & No & 152 & $0.734(0.521-0.841)$ & \multirow[t]{2}{*}{$<0.001 *$} & $60(50-80)$ & \multirow[t]{2}{*}{$<0.001^{*}$} \\
\hline & Yes & 228 & $0.513(0.301-0.724)$ & & $60(50-70)$ & \\
\hline $\begin{array}{l}\text { Health utility score } \\
\text { and EQ-VAS score } \\
\text { scores and EQ-VAs }\end{array}$ & $\begin{array}{l}\text { EQ-VAS sc } \\
\text { ate a bette } \\
s \text { betweer }\end{array}$ & $\begin{array}{l}\text { s are disp } \\
\text { ealth-relat } \\
\text { o levels of }\end{array}$ & $\begin{array}{l}\mathrm{d} \text { as the median and } \\
\text { uality of life. Mann-Wr } \\
\text { ch subgroup. *Significe }\end{array}$ & $\begin{array}{l}\text { artile range } \\
\text { est was us } \\
\text { erence. }\end{array}$ & $\begin{array}{l}\text { R). Higher healt } \\
\text { o compare the }\end{array}$ & $\begin{array}{l}\text { ty scores } \\
\text { utility }\end{array}$ \\
\hline $\begin{array}{l}\text { Abbreviations: MS } \\
\text { cerebellar ataxia. } \\
\text { movement sleep b } \\
\text { cognitive impairm }\end{array}$ & $\begin{array}{l}\text { iple syste } \\
\text { visual a } \\
\text { ral disord }\end{array}$ & $\begin{array}{l}\text { trophy. M } \\
\text { g scale. O } \\
\text { D-SP: Par }\end{array}$ & $\begin{array}{l}\text { : MSA with predomin } \\
\text { rthostatic hypotensior } \\
\text { on's disease-related sl }\end{array}$ & $\begin{array}{l}\text { arkinsonisi } \\
\text { Excessive } \\
\text { blems. FL }\end{array}$ & $\begin{array}{l}\text { 1SA-C: MSA wit } \\
\text { time sleepines } \\
\text { rontal lobe dysf }\end{array}$ & $\begin{array}{l}\text { dominately } \\
\text { ): Rapid eye } \\
\text { on. Cl: }\end{array}$ \\
\hline
\end{tabular}




\section{Related factors of EQ-5D-5L scores in total MSA patients and patients with two subtypes}

Spearman's analysis showed a moderate correlation between the EQ-VAS score and scores of total UMSARS, FSS, PDSS-2, HAMD, and HAMA in total MSA patients. The total UMSARS score was strongly correlated with health utility value. Scores for FAB, MoCA, FSS, PDSS-2, HAMD, and HAMA had weak to moderate correlations with health utility value in total MSA patients. (Table 3)

Table 3

Spearman correlation between EQ-VAS score, health utility index and clinical characteristics of MSA.

\begin{tabular}{|lllll|}
\hline & EQ-VAS score $(r)$ & P value & Health utility value $(r)$ & P value \\
\hline UMSARS-total & -0.379 & $<0.001^{*}$ & -0.717 & $<0.001^{*}$ \\
\hline FAB & 0.144 & $0.005^{\star}$ & 0.246 & $<0.001^{*}$ \\
\hline MoCA & 0.154 & $0.003^{*}$ & 0.289 & $<0.001^{*}$ \\
\hline FSS & -0.253 & $<0.001^{*}$ & -0.380 & $<0.001^{*}$ \\
\hline PDSS-2 & -0.304 & $<0.001^{*}$ & -0.356 & $<0.001^{*}$ \\
\hline ESS & -0.029 & 0.579 & -0.101 & 0.049 * \\
\hline RBDSQ & -0.075 & 0.142 & -0.110 & $0.031^{\star}$ \\
\hline HAMD & -0.380 & $<0.001^{*}$ & -0.564 & $<0.001^{*}$ \\
\hline HAMA & -0.359 & $<0.001^{*}$ & -0.479 & $<0.001^{*}$
\end{tabular}

The correlation coefficient $(r) \geq 0.8$ is defined as a very strong correlation; $0.60-0.79$, a strong correlation; $0.4-0.59$, a moderate correlation; 0.20-0.39, a weak correlation; and $r \leq 0.19$, a negligible correlation. *Significant difference.

Abbreviations: MSA: multiple system atrophy. EQ-VAS: visual analog scale. UMSARS: the Unified Multiple System Atrophy Rating Scale. FAB: the frontal assessment battery. MoCA: the Montreal Cognitive Assessment. FSS: the Fatigue Severity Scale. PDSS-2: the Parkinson's Disease Sleep Scale 2nd version. ESS: the Epworth Sleepiness Scale. RBDSQ: Rapid Eye Movement Sleep Behavior Disorder Screening Questionnaire. HAMD: the Hamilton Depression Rating Scale. HAMA: the Hamilton Anxiety Rating Scale.

Multivariate logistic models showed the determinants of health utility value and EQ-VAS score in total MSA and two subtypes of patients. (Table 4) In the total MSA patients, female sex, fatigue, PD-SP, and greater total UMSARS score were the determinants for the lower health utility values. Fatigue, PD-SP, anxiety emotion, and greater total UMSARS score were the determinants for the lower EQ-VAS scores. There were some differences in the determinants for health utility value and EQ-VAS score between patients with MSA-C and MSA-P. For example, cognitive impairment was the determinant for lower health utility value in patients with MSA-P but not in patients with MSA-C. And frontal lobe dysfunction was the determinant for lower EQ-VAS score in patients with MSA-P but not in those with MSA-C. More details are displayed in Table 4. 
Table 4

Multivariate logistic regression analysis of healthy utility index and EQ-VAS score for MSA and two subtypes.

\begin{tabular}{|c|c|c|c|c|c|c|c|c|c|c|c|c|}
\hline & MSA & & & & $\begin{array}{l}\text { MSA- } \\
\mathrm{C}\end{array}$ & & & & $\begin{array}{l}\text { MSA- } \\
P\end{array}$ & & & \\
\hline & $\begin{array}{l}\text { Health } \\
\text { utility } \\
\text { value }\end{array}$ & & $\begin{array}{l}\text { EQ- } \\
\text { VAS } \\
\text { score }\end{array}$ & & $\begin{array}{l}\text { Health } \\
\text { utility } \\
\text { value }\end{array}$ & & $\begin{array}{l}\text { EQ- } \\
\text { VAS } \\
\text { score }\end{array}$ & & $\begin{array}{l}\text { Health } \\
\text { utility } \\
\text { value }\end{array}$ & & $\begin{array}{l}\text { EQ- } \\
\text { VAS } \\
\text { score }\end{array}$ & \\
\hline & $\begin{array}{l}\text { OR } \\
(95 \% \\
\mathrm{Cl})\end{array}$ & $\begin{array}{l}P \\
\text { value }\end{array}$ & $\begin{array}{l}\text { OR } \\
(95 \% \\
\mathrm{Cl})\end{array}$ & $\begin{array}{l}P \\
\text { value }\end{array}$ & $\begin{array}{l}\text { OR } \\
(95 \% \\
\mathrm{Cl})\end{array}$ & $\begin{array}{l}P \\
\text { value }\end{array}$ & $\begin{array}{l}\text { OR } \\
(95 \% \\
\mathrm{Cl})\end{array}$ & $\begin{array}{l}P \\
\text { value }\end{array}$ & $\begin{array}{l}\text { OR } \\
(95 \% \\
\mathrm{Cl})\end{array}$ & $\begin{array}{l}P \\
\text { value }\end{array}$ & $\begin{array}{l}\text { OR } \\
(95 \% \\
\mathrm{Cl})\end{array}$ & $\begin{array}{l}P \\
\text { value }\end{array}$ \\
\hline $\begin{array}{l}\text { UMSARS- } \\
\text { total }\end{array}$ & $\begin{array}{l}1.18 \\
(1.14- \\
1.22)\end{array}$ & $<0.001$ & $\begin{array}{l}1.04 \\
(1.02- \\
1.06)\end{array}$ & $<0.001$ & $\begin{array}{l}1.17 \\
(1.12- \\
1.23)\end{array}$ & $<0.001$ & $\begin{array}{l}1.04 \\
(1.01- \\
1.07)\end{array}$ & 0.003 & $\begin{array}{l}1.20 \\
(1.13- \\
1.27)\end{array}$ & $<0.001$ & $\begin{array}{l}1.04 \\
(1.01- \\
1.07)\end{array}$ & 0.007 \\
\hline Fatigue & $\begin{array}{l}2.30 \\
(1.28- \\
4.09)\end{array}$ & 0.005 & $\begin{array}{l}1.64 \\
(1.02- \\
2.65)\end{array}$ & 0.042 & $\begin{array}{l}2.83 \\
(1.13- \\
5.96)\end{array}$ & 0.006 & & & & & $\begin{array}{l}2.20 \\
(1.01- \\
4.77)\end{array}$ & 0.047 \\
\hline PD-SP & $\begin{array}{l}2.78 \\
(1.30- \\
5.97)\end{array}$ & 0.009 & $\begin{array}{l}1.86 \\
(1.06- \\
3.26)\end{array}$ & 0.031 & & & $\begin{array}{l}2.91 \\
(1.16- \\
7.31)\end{array}$ & 0.023 & $\begin{array}{l}4.42 \\
(1.53- \\
12.82)\end{array}$ & 0.006 & & \\
\hline $\begin{array}{l}\text { Anxiety } \\
\text { mood }\end{array}$ & & & $\begin{array}{l}2.23 \\
(1.29- \\
3.88)\end{array}$ & 0.004 & & & & & & & $\begin{array}{l}4.65 \\
(1.76- \\
12.31)\end{array}$ & 0.002 \\
\hline $\begin{array}{l}\text { Depressive } \\
\text { mood }\end{array}$ & & & & & & & $\begin{array}{l}1.97 \\
(1.02- \\
3.80)\end{array}$ & 0.045 & & & & \\
\hline $\mathrm{Cl}$ & & & & & & & & & $\begin{array}{l}2.69 \\
(1.12- \\
6.46)\end{array}$ & 0.027 & & \\
\hline FLD & & & & & & & & & & & $\begin{array}{l}2.33 \\
(1.09- \\
4.98)\end{array}$ & 0.030 \\
\hline Sex & $\begin{array}{l}0.35 \\
(0.20- \\
0.62)\end{array}$ & $<0.001$ & & & $\begin{array}{l}0.26 \\
(0.12- \\
0.56)\end{array}$ & 0.001 & $\begin{array}{l}0.49 \\
(0.27- \\
0.91)\end{array}$ & 0.023 & & & & \\
\hline \multicolumn{13}{|c|}{ Variables that are statistically significant in the model are shown in the table. } \\
\hline \multicolumn{13}{|c|}{$\begin{array}{l}\text { Abbreviations: MSA: multiple system atrophy. EQ-VAS: visual analog scale. MSA-P: MSA with predominately parkinsonism. } \\
\text { MSA-C: MSA with predominately cerebellar ataxia. OR: odds ratio. } 95 \% \mathrm{Cl}: 95 \% \text { confidence interval. UMSARS: the Unified Multiple } \\
\text { System Atrophy Rating Scale. PD-SP: Parkinson's disease-related sleep problems. FLD: frontal lobe dysfunction. Cl: cognitive } \\
\text { impairment. }\end{array}$} \\
\hline
\end{tabular}

\section{Discussion}

Our research measured the HRQoL of MSA using EQ-5D-5L, providing important data on the QoL of Chinese MSA patients. We found that patients with MSA in a Chinese population had poor HRQoL. Mobility was the most commonly reported problem and pain/discomfort was the least common problem, which was consistent with the previous study using EQ-5D-3L. [4] Besides disease severity, sex, fatigue, and PD-SP were found to be the determinants for health utility value of MSA, and anxiety symptom, fatigue, and PD-SP were the determinants for EQ-VAS of MSA. Additionally, we found there were some differences in the determinants for HRQoL of MSA between MSA-C and MSA-P patients.

The mean health utility index (0.558) and the mean EQ-VAS score (59.5) of patients with MSA were lower than those of the Chinese healthy population $(0.943,82.9)$ and those of patients with coronary heart disease and stroke history $(0.850,61.0)$. [23, 24] The mean EQ-VAS score of Chinese patients with MSA (59.5) was higher than the results of the European study $(44.5$ and 36.9$)$. [4, 5] This may be explained by the shorter disease duration and mild disease severity of patients enrolled in our study. Consistent with 
the previous study, we also found that the total UMSARS score was the determinant of health utility value and VAS scores in the MSA and two subtypes. [4]

We found that mobility was the most commonly reported problem and pain/discomfort was the least common problem, which was consistent with previous studies. [4, 5] Furthermore, we found that a higher frequency of problem of mobility was reported in patients with MSA-C than patients with MSA-P, which was consistent with the previous study assessed by EQ-5D-3L. [4] However, we found there was no difference in the mean scores of motor examination and global disability scale of UMSARS between the two subtypes. Our finding suggested that UMSARS has limited ability to reflect mobility in patients with MSA-C. In addition, we found that patients with MSA-P reported more pain/discomfort than patients with MSA-C, which was consistent with the previous study assessed with EQ-5D-3L. [5] This may be due to the severer damage in the basal ganglia in MSA-P than in MSA-C. [25]

Depression was reported to be a determinant of the QoL of MSA.[3, 4, 26, 27] In our study, the depressive emotion was related to the EQ-VAS score of MSA-C. We also found that anxiety played an important role in the decreasing EQ-VAS score of MSA. [3] Attempts to treat these symptoms are important to improve the HRQoL of patients with MSA. Similar to the result of the previous study, we found that female sex was a negative determinant of health utility values of MSA. [4] Additionally, females were more likely to initially manifest motor symptoms and recurrent falls within three years. [28] More researches should be made to understand the gender difference in MSA.

Fatigue is common in several neurological diseases including PD and multiple sclerosis. [29] There were 29-82\% of MSA patients who suffered from fatigue. [30], which was significantly higher than that of patients with PD and healthy control. [31] In the current study, we found that fatigue was negatively correlated with health utility value and EQ-VAS score of MSA, which was consistent with our previous study evaluating QoL of MSA patients using PDQ-39. [11] The pathological mechanisms of fatigue are still uncertain. A study found that fatigue in MSA was related to the decrease of the 5-hydroxytryptamine receptor in the raphe nuclei and brain stem. [31] We should pay more attention on fatigue when managing patients with MSA.

In our previous study, sleep-related disorders including PD-SP, RBD, and EDS were found to be associated with higher disease severity in MSA. [32] In the current study, PD-SP but not RBD and EDS was found to be a determinant of the health utility value and EQ-VAS score of MSA. Since PD-SP includes motor symptoms at night, PD symptoms at night, and disturbed sleep, the etiology of $\mathrm{PD}-\mathrm{SP}$ in MSA is complex and is still under research. Management of PD-SP in MSA is necessary.

Recent studies found that a varying degree of cognitive impairment was common in MSA assessed by comprehensive neuropsychological testing. [33,34] Our current study found that cognitive impairment was the determinant of health utility value in MSA-P but not in MSA-C. $[35,36]$ Kawai reported that patients with MSA-P had wider and severer cognitive impairment than patients with MSA-C. [35] Patients with MSA-P were reported to have lower MoCA scores than patients with MSA-C in a Chinese study. [37] Additionally, we found that frontal lobe dysfunction was the determinant of EQ-VAS score in MSA-P but not in MSA-C, which was similar to our previous finding that frontal lobe dysfunction was the determinant of HRQoL assessed by PDQ-39 in MSA. [26] Further study should pay attention to the cognitive function in patients with MSA.

This research had several limitations. First, this cross-sectional research explored the features and determinants of the EQ-5D-5L score in MSA. Further study should concentrate on the longitudinal change of the EQ-5D-5L scores of MSA. Second, the diagnosis of MSA was based on the clinical features but not the autopsy. Further study should build autopsy confirmed cohort to study the HRQoL of MSA.

\section{Conclusion}

The current research found that MSA patients had poor HRQoL and EQ-5D-5L was a validating tool to evaluate HRQoL in MSA. The determinants of lower health utility value were female sex, greater scores of total UMSARS, fatigue, and PD-SP while that of lower EQ-VAS scores were greater scores of total UMSARS, fatigue, PD-SP, and anxiety symptom. In addition, the determinants of EQ-5D$5 \mathrm{~L}$ were different between patients with MSA-C and MSA-P. This research provided important information on the HRQoL and potential determinants of MSA, helping developing intervention strategies to improve their health status.

\section{Declarations}

Page $8 / 11$ 
Funding

This work is funded by the National Key Research and Development Program of China (Grant No. 2016YFC0901504), the 1.3.5 project for disciplines of excellence, West China Hospital, Sichuan University (Grant No. ZY2016203), and the Science Foundation of Chengdu Science and Technology Bureau (2019-YF05-00307-SN).

\section{Acknowledgments}

This study was supported by the EuroQol Group. We thank all subjects for participating in this study.

\section{Author Contribution}

Yi Xiao: Organization and execution of research project, design, and execution of statistical analysis, writing of the draft, review, and critique of the manuscript; Lingyu Zhang: Organization and execution of research project, design, and execution of statistical analysis, review, and critique of the manuscript; Qianqian Wei: Organization and execution of research project, design the statistical analysis; Tianmi Yang, Kuncheng Liu, Ruwei Ou, Yanbing Hou and Junyu Lin: Organization and Execution of research project; Huifang Shang: Conception, organization and execution of research project, review and critique of the manuscript.

\section{Ethics approval and consent to participate}

This study was approved by the institutional ethics committee of West China Hospital and informed consents were obtained from all the participants of the study.

\section{Consent for publication}

Not applicable.

\section{Availability of data and materials}

The data used in the current study are available from the corresponding author on reasonable request.

\section{Competing interests}

The authors declare that they have no competing interests.

\section{References}

1. Gilman S, Wenning GK, Low PA, Brooks DJ, Mathias CJ, Trojanowski JQ, Wood NW, Colosimo C, Dürr A, Fowler CJ, et al: Second consensus statement on the diagnosis of multiple system atrophy.Neurology 2008, 71:670-676.

2. Benrud-Larson LM, Sandroni P, Schrag A, Low PA: Depressive symptoms and life satisfaction in patients with multiple system atrophy.Mov Disord 2005, 20:951-957.

3. Du JJ, Wang T, Huang P, Cui S, Gao C, Lin Y, Fu R, Zhou H, Chen S: Clinical characteristics and quality of life in Chinese patients with multiple system atrophy.Brain Behav 2018, 8:e01135.

4. Winter Y, Spottke AE, Stamelou M, Cabanel N, Eggert K, Höglinger GU, Sixel-Doering F, Herting B, Klockgether T, Reichmann H, et al: Health-related quality of life in multiple system atrophy and progressive supranuclear palsy.Neurodegener Dis 2011, 8:438446.

5. Schrag A, Geser F, Stampfer-Kountchev M, Seppi K, Sawires M, Köllensperger M, Scherfler C, Quinn N, Pellecchia MT, Barone P, et al: Health-related quality of life in multiple system atrophy.Mov Disord 2006, 21:809-815.

6. Jecmenica-Lukic MV, Pekmezovic TD, Petrovic IN, Dragasevic NT, Kostić VS: Factors associated with deterioration of healthrelated quality of life in multiple system atrophy: 1-year follow-up study.Acta Neurol Belg 2018, 118:589-595.

7. Schrag A, Jenkinson C, Selai C, Mathias C, Quinn N: Testing the validity of the PDQ-39 in patients with MSA.Parkinsonism Relat Disord 2007, 13:152-156. 
8. Herdman M, Gudex C, Lloyd A, Janssen M, Kind P, Parkin D, Bonsel G, Badia X: Development and preliminary testing of the new five-level version of EQ-5D (EQ-5D-5L).Qual Life Res 2011, 20:1727-1736.

9. Thompson AJ, Turner AJ: A Comparison of the EQ-5D-3L and EQ-5D-5L.Pharmacoeconomics 2020, 38:575-591.

10. Higginson IJ, Gao W, Saleem TZ, Chaudhuri KR, Burman R, McCrone P, Leigh PN: Symptoms and quality of life in late stage Parkinson syndromes: a longitudinal community study of predictive factors. PLoS One 2012, 7:e46327.

11. Zhang L, Cao B, Ou R, Wei QQ, Zhao B, Yang J, Wu Y, Shang H: Non-motor symptoms and the quality of life in multiple system atrophy with different subtypes.Parkinsonism Relat Disord 2017, 35:63-68.

12. Wenning GK, Tison F, Seppi K, Sampaio C, Diem A, Yekhlef F, Ghorayeb I, Ory F, Galitzky M, Scaravilli T, et al: Development and validation of the Unified Multiple System Atrophy Rating Scale (UMSARS).Mov Disord 2004, 19:1391-1402.

13. Nasreddine ZS, Phillips NA, Bédirian V, Charbonneau S, Whitehead V, Collin I, Cummings JL, Chertkow H: The Montreal Cognitive Assessment, MoCA: a brief screening tool for mild cognitive impairment.J Am Geriatr Soc 2005, 53:695-699.

14. Chen KL, Xu Y, Chu AQ, Ding D, Liang XN, Nasreddine ZS, Dong Q, Hong Z, Zhao QH, Guo QH: Validation of the Chinese Version of Montreal Cognitive Assessment Basic for Screening Mild Cognitive Impairment.J Am Geriatr Soc 2016, 64:e285-e290.

15. Dubois B, Slachevsky A, Litvan I, Pillon B: The FAB: a Frontal Assessment Battery at bedside.Neurology 2000, 55:1621-1626.

16. Hamilton M: Development of a rating scale for primary depressive illness.Br J Soc Clin Psychol 1967, 6:278-296.

17. Clark DB, Donovan JE: Reliability and validity of the Hamilton Anxiety Rating Scale in an adolescent sample.J Am Acad Child Adolesc Psychiatry 1994, 33:354-360.

18. Friedman JH, Alves G, Hagell P, Marinus J, Marsh L, Martinez-Martin P, Goetz CG, Poewe W, Rascol O, Sampaio C, et al: Fatigue rating scales critique and recommendations by the Movement Disorders Society task force on rating scales for Parkinson's disease.Mov Disord 2010, 25:805-822.

19. Horvath K, Aschermann Z, Acs P, Deli G, Janszky J, Karadi K, Komoly S, Faludi B, Kovacs N: Test-retest validity of Parkinson's disease sleep scale 2nd version (PDSS-2).J Parkinsons Dis 2014, 4:687-691.

20. Johns MW: A new method for measuring daytime sleepiness: the Epworth sleepiness scale.Sleep 1991, 14:540-545.

21. Stiasny-Kolster K, Mayer G, Schafer S, Moller JC, Heinzel-Gutenbrunner M, Oertel WH: The REM sleep behavior disorder screening questionnaire-a new diagnostic instrument.Mov Disord 2007, 22:2386-2393.

22. Luo N, Liu G, Li M, Guan H, Jin X, Rand-Hendriksen K: Estimating an EQ-5D-5L Value Set for China.Value Health 2017, 20:662669.

23. Yang Z, Busschbach J, Liu G, Luo N: EQ-5D-5L norms for the urban Chinese population in China. Health Qual Life Outcomes 2018, 16:210.

24. Mei Y-X, Wu H, Zhang H-Y, Hou J, Zhang Z-X, Liao W, Liu X-T, Sang S-X, Mao Z-X, Yang D-B, et al: Health-related quality of life and its related factors in coronary heart disease patients: results from the Henan Rural Cohort study.Scientific reports 2021, 11:5011-5011.

25. Lin J, Xu X, Hou Y, Yang J, Shang H: Voxel-Based Meta-Analysis of Gray Matter Abnormalities in Multiple System Atrophy.Front Aging Neurosci 2020, 12:591666.

26. Zhang L, Cao B, Zou Y, Wei QQ, Ou R, Zhao B, Yang J, Wu Y, Shang H: Frontal lobe function, behavioral changes and quality of life in patients with multiple system atrophy.Restor Neurol Neurosci 2019, 37:11-19.

27. Torny F, Lacoste M, Videaud H, Chouly M, Parveau MC, Couratier P: [Comparison of quality of life in multiple system atrophy and Parkinson's disease].Rev Neurol (Paris) 2009, 165:911-915.

28. Coon EA, Nelson RM, Sletten DM, Suarez MD, Ahlskog JE, Benarroch EE, Sandroni P, Mandrekar JN, Low PA, Singer W: Sex and gender influence symptom manifestation and survival in multiple system atrophy.Auton Neurosci 2019, 219:49-52.

29. Kluger BM, Krupp LB, Enoka RM: Fatigue and fatigability in neurologic illnesses: proposal for a unified taxonomy.Neurology 2013, 80:409-416.

\section{Figures}



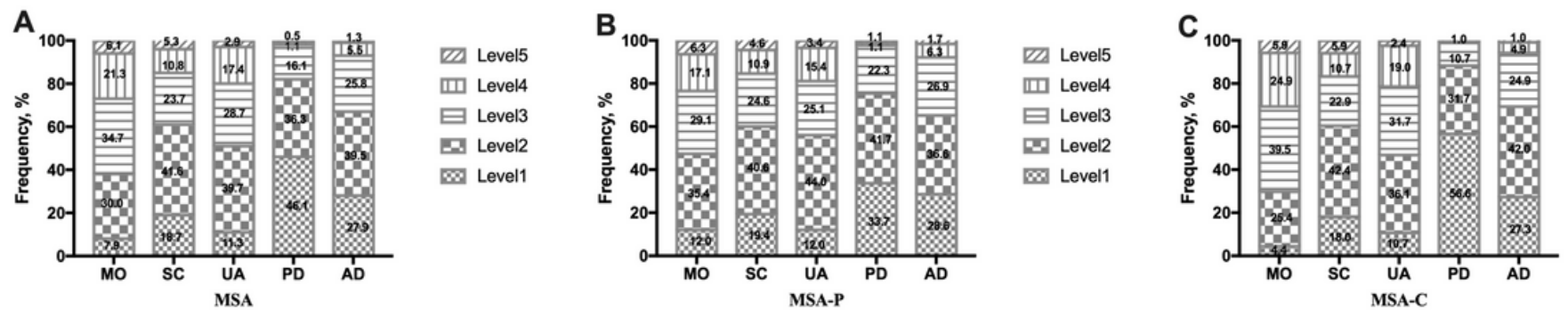

ש Level5

[2] Level5

III Level4

III Level4

$\boxminus$ Level3

므 Level2

[ Level1

미민 Level2

Level1

III Level4

曰 Level3

믐 Level2

W Level1

Figure 1

Distribution of 5 levels in each dimension of EQ-5D-5L. Figure A: EQ-5D-5L of total MSA; Figure B: EQ-5D-5L of patients with MSA-P; Figure C: EQ-5D-5L of patients with MSA-C. Level 1: no problems, level 2: mild problems, level 3: moderate problems, level 4: severe problems, level 5: extreme problems. Abbreviations: EQ-5D-5L: the five-level EuroQol-5 dimensions. MSA: multiple system atrophy. MSA-P: MSA with predominately parkinsonism. MSA-C: MSA with predominately cerebellar ataxia. MO: Mobility, SC: Self-care, UA: Usual activities, PD: Pain/discomfort, AD: Anxiety/depression.

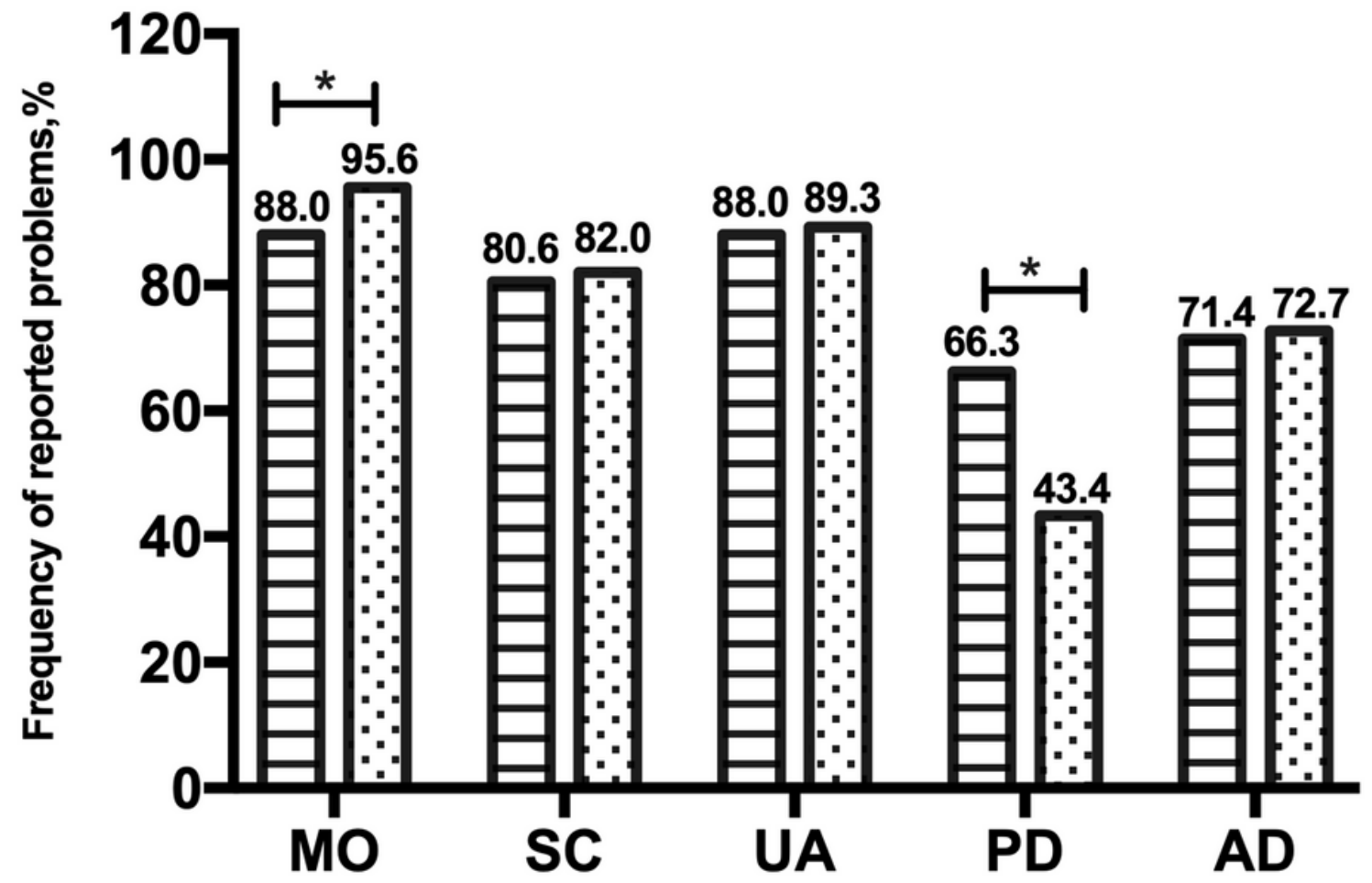

Figure 2

Frequency of reported problems for each dimension of EQ-5D-5L between MSA-P and MSA-C patients. *Significant difference. Abbreviations: EQ-5D-5L: the five-level EuroQol-5 dimensions. MSA: multiple system atrophy. MSA-P: MSA with predominately parkinsonism. MSA-C: MSA with predominately cerebellar ataxia. MO: Mobility, SC: Self-care, UA: Usual activities, PD:

Pain/discomfort, AD: Anxiety/depression. 